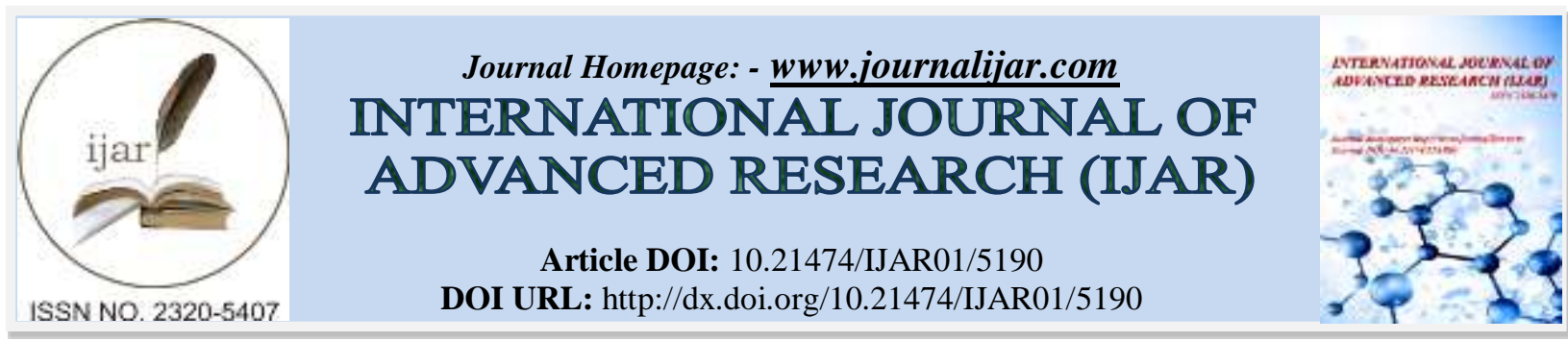

RESEARCH ARTICLE

\title{
ANESTHETIC MANAGEMENT OF A PATIENT WITH CONGENITAL CYANOTIC HEART DISEASE (TOF) UNDERGOING CARDIAC SURGERY. AN ANTICIPATED DIFFICULT INDUCTION.
}

Dr. Chanshetty rajnish ${ }^{1}$, Dr. nimishjain ${ }^{2}$, Dr. arun kumar haridas ${ }^{3}$ and Dr. Rama upadhayaya ${ }^{4}$.

1. (Sr, chanshettyrajnish), Department of anaesthesiology, s.b.k.s. M.i. \& r.c. Sumandeep Vidhyapeeth, Piparia.

2. (asst.professor,cardiacanaeshtetist), Department of anaesthesiology, s.b.k.s. M.i. \& r.c. Sumandeep Vidhyapeeth, Piparia.

3. (ctvs surgeon), Department of anaesthesiology, s.b.k.s. M.i. \& r.c. Sumandeep Vidhyapeeth, Piparia.

4. (professor\& head), Department of anaesthesiology, s.b.k.s. M.i. \& r.c. Sumandeep Vidhyapeeth, Piparia.

\section{Manuscript Info}

Manuscript History

Received: 16 June 2017

Final Accepted: 18 July 2017

Published: August 2017

\section{Abstract}

Copy Right, IJAR, 2017,. All rights reserved.

\section{Introduction:-}

- TOF tetralogy of fallot is the commonest cause of cyanotic CHD in children, accounting for $10 \%$ of CHD.

- Occurs in 3-6 infants for every 10,000 births. This disorder accounts for one third of all CHD in patients younger than 15 years.

- commonly in males than in females.

- Genetic studies indicate that in some patients with tetralogy of Fallot, there may be 22q11.2 deletion and other submicroscopic copy number alterations.

- The prevalence of congenital heart defects within India is approximately 4 cases per 1,000 live births with TOF comprising 7 to $32 \%$ of these cases, making it among the most common congenital anomalies.

- Tetralogy of Fallot,

- Right ventricular (RV) outflow tract obstruction (RVOTO)

- Ventricular septal defect (VSD),

- Aorta dextroposition,

- RV hypertrophy

- Difficulty with feeding

- Failure to thrive

- Episodes of bluish pale skin during crying or feeding (ie, "Tet" spells)

- Exertional dyspnea, usually worsening with age

- Cyanosis of the lips and nail bed is usually pronounced at birth

- After age 3-6 months, the fingers and toes show clubbing

Corresponding Author:- Chanshetty rajnish.

Address:- (Sr, chanshettyrajnish), Department of anaesthesiology, s.b.k.s. M.i. \& r.c. Sumandeep

Vidhyapeeth, Piparia. 


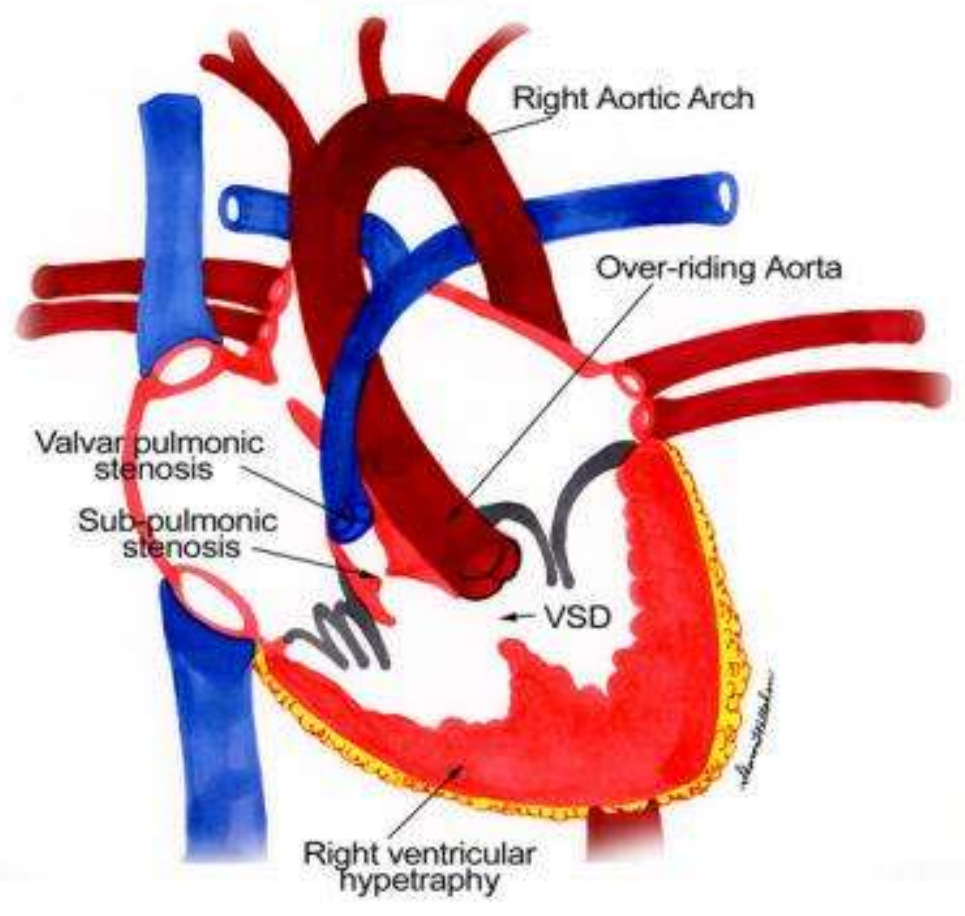

\section{Case report:-}

- 13years old, male child weighing $24 \mathrm{~kg}$ came with complain of severe breathlessness since 4 to 5 years mild in nature gradually progressive at present patient is bed ridden \& unable to talk \& walk, asso with anxiety, up rolling of eyes, protrusion of tongue, central cyanosis and generalized, bluish discoloration of nail bed palms and soles, clubbing grade IV and child maintaining saturation of 40\% @5lit $\mathrm{O} 2 / \mathrm{min}$ on ventimask with previously diagnosed congenital cyanotic heart disease (tetralogy of fallot), posted for tof repair that is total intracardiac repair.
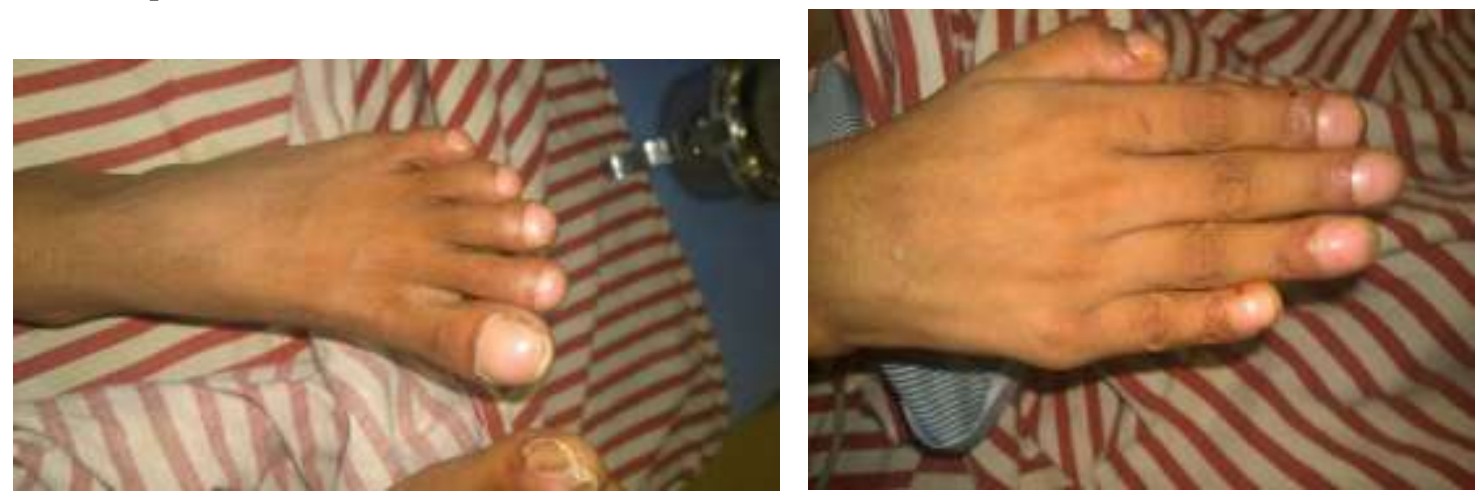

\section{Aims \& Objectives:-}

- To induce patient smoothly with severe uncorrected tetralogy of fallot, while maintaining oxygen saturation and blood pressure, secure and manage airway by endotracheal intubation in an anticipated difficult induction.

- To increase the pulmonary blood flow by maintaining systemic vascular resistance.

\section{General Physical Examination:-}

patient conscious \& oriented

Vitals :

Temp - Afebrile

Pulse- 96/min.

BP- 102/60 mm hg 


\section{R.R.-24/min.}

SPO2-40@5lit/min

- General examination :

Pallor :- ve

Icterus : -ve

Clubbin:g : Grade IV

Cyanosis : +++

Peripheral Oedema: -ve

Lymphadenopathy: -ve

- Systemic examination :

$\mathrm{R} / \mathrm{S}-\mathrm{A} / \mathrm{E} \mathrm{B} / \mathrm{L}$ equal / no added sounds.

CVS $-S_{1} \& S_{2}$ heard, pansystolic murmur present

$\mathrm{CNS}$ - conscious \& oriented NAD

P/A - soft non tender, bowel sounds resent

\section{Airway and Spine Assessment:}

- Mouth opening - 3 fingers

- All teeth intact

- $\quad$ MPG - Grade I

- Neck movement - normal extension \& flexion

- $\quad$ Back \& Spine - Normal

\begin{tabular}{|c|c|}
\hline - $\quad$ Blood Report & - $\quad$ Patient Values \\
\hline - $\quad \mathbf{H b}$ & - $\quad 18.8 \mathrm{gm} \%$ \\
\hline - $\quad$ TLC & - $\quad 6,200 / \mathrm{cu} \mathrm{mm}$ \\
\hline - $\quad$ DLC P/L/M/E & - $50 / 43 / 3 / 4 \%$ \\
\hline - $\quad$ Plt & $\begin{array}{ll} & \mathbf{8 0 , 0 0 0 c e l l s} \text { per cu } \mathrm{mm} \\
\end{array}$ \\
\hline - $\quad$ Bld. Urea & - $\quad 32 \mathrm{mg} / \mathrm{dl}$ \\
\hline - $\quad$ Sr. Creat & - $1 \mathrm{mg} / \mathrm{dl}$ \\
\hline • S. Bil. & $\begin{array}{ll}\bullet & \text { T- } 0.5 \mathrm{mg} / \mathrm{dl} \\
\bullet & \text { D }-0.4 \mathrm{mg} / \mathrm{dl} \\
\bullet & \text { ID }-0.1 . \mathrm{mg} / \mathrm{dl} \\
\end{array}$ \\
\hline • $\quad$ SGOT/ SGPT & - $35 / 40 \mathrm{U} / \mathrm{L}$ \\
\hline - $\quad$ RBS & - $\quad 102 \mathrm{mg} / \mathrm{d}$ \\
\hline PT & $\begin{array}{l}14 \mathrm{sec} \\
14 \mathrm{sec}\end{array}$ \\
\hline INR & 2.4 \\
\hline APTT & $\begin{array}{l}26.4 \mathrm{sec} \\
26.4 \mathrm{sec}\end{array}$ \\
\hline
\end{tabular}

- $\quad$ Chest X-ray

- classical appearance of

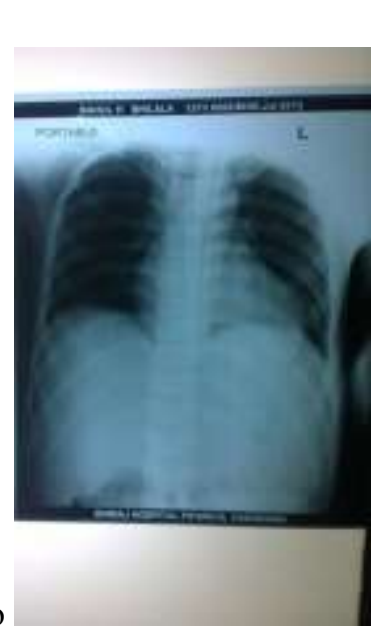

- 'boot shaped heart' due to

- Pulmonary oligemia (oligemic lung) 
- Upturned cardiac apex

- It aortic arch

- ECG -Signs of right ventricular hypertrophy and right axis deviation.

- 2DECHO s/o congenital cyanotic heart disease, tetralogy of fallot with severe pulmonary stenosis, Left aortic arch, mild AR, Large malaligned subaortic VSD with right to left shunt.

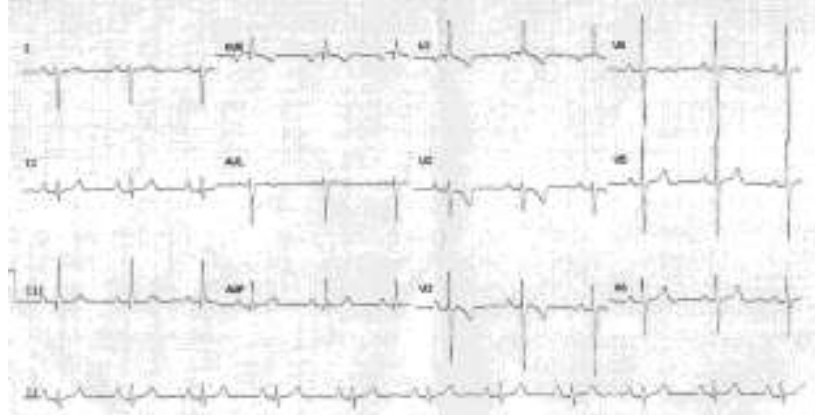

- PRE -OPERATIVE PREPARATION

- Informed \& written consent(ASA III) for anaesthesia was taken.

- Patient was kept NBM over night.

- Pre operatively patient was on inj propranolol \& adequate IV fluids for maintainance.

- The patient was shifted to the OT from recovery room.

- After securing an IV line with 18 G IV cannula in the left upper limb, CVP line in rt IJV and arterial line in right femoral line, standard monitors [ECG, pulse oximeter, invasive blood pressure (IBP), end-tidal carbon dioxide (ETCO2)] were attached and the baseline vitals recorded.

- Blood pressure - 104/60 mmHg,

- Heart rate- 98 beats/min

- SpO2-40\% @ 5lit/min

INTRA OP MONITORING

- The patient was pre oxygenated with $100 \%$ oxygen for 5 minutes,

\section{PREMEDICATION}

- Inj.Glycopyrrolate $0.004 \mathrm{mg} / \mathrm{kg}$ iv

- Inj.midazolam $0.02-0.05 \mathrm{mg} / \mathrm{kg}$ iv

INDUCTION

- Inj ondensatron $2 \mathrm{mg}$.

- Inj .fentanyl $5 \mathrm{mcg} / \mathrm{kg}$

- Ketamine $1-2 \mathrm{mg} / \mathrm{kg}$

- A pressor agent (phenyephrine) would be given to the patient accordingly to maintain BP.

- Inj. Succinylcholine $2 \mathrm{mg} / \mathrm{kg}$ IV

- Minimum PPV were given.

- Oral intubation done with cuffed Endo Tracheal tube no.6.5mm I.D

- ET tube position was confirmed clinically by chest auscultation and capnography and tube fixed.

- Avoid PEEP or minimum PEEP

- INTRA OP monitoring

MAINTENANCE OF ANAESTHESIA

- It will be connected to anaesthesia machine. Patient will be ventilated with $100 \%$ oxygen along with inhalation agent sevoflurane $1-2 \%$ and intravenous inj vecuronium. $0.1 \mathrm{mg} / \mathrm{kg}$

- After intubation vitals are

- $\quad$ SPO2- $78 \%$ (on $100 \%$ oxygen)

- BP- $120 / 70 \mathrm{mmhg}$

- $\mathrm{PR}-92 / \mathrm{min}$

- Hemodynamic parameters were stable throughout the operation.

- Totally, he received $60-80 \mathrm{ml} / \mathrm{kg} / \mathrm{hr} \mathrm{RL}$ and had $250 \mathrm{~mL}$ of urine output.

\section{REVERSAL}

- Inj.Glycopyrolate $0.008 \mathrm{mg} / \mathrm{kg}$ IV and Neostigmine $0.05 \mathrm{mg} / \mathrm{kg}$ IV 
- Pt was extubated after adequate recovery

- DISCUSSION AND ANAESTHESIA CONCERN

Our purpose of choosing certain specific things are to increase pulmonary blood flow and improve oxygen saturation.

\section{- Perioperative concerns}

- Increase in PVR or decrease in SVR leading to Right to Left shunt

- Tet Spells pre induction (crying/anxiety)

- Polycythemia and bleeding

- Air embolus

- RV failure

- $\quad \mathrm{GOAL}=\uparrow \mathrm{SVR}$ and $\downarrow \mathrm{PVR} \rightarrow \downarrow \mathrm{R}-\mathrm{L}$ shunt

\section{KETAMINE}

- Sympathomimetic effects help maintain HR, SVR, MAP and contractility..

- Infusion of minimum dose of Nor Adr was started from the beginning of induction to increase SVR. B-blocker

- Pre operatively patient was on inj propranolol \& adequate IV fluids for maintainance.

\section{Discussion And Anaesthesia Concern:-}

- Expecting a difficult induction in this case as the patient is maintaining O2 saturation of $40 \%$ with $\mathrm{O} 2$ @5lit/min via venti mask \& the risk of fall in BP extensively; we kept patient in head down position, started $100 \%$ O2 \& kept the emergency cart ready.

- $100 \%$ oxygen reduces PVR (pulmonary vasodilator action).

- Trendelenburg position to improve venous return and avoids TET spell.

- Minimum PPV to maintain PVR.

- Phenylephrine (alpha 1 adrenergic agonist) its vasoconstriction effect increases SVR.

- IV fluid according to the weight of patient.

- No PEEP or minimum PEEP helps maintain adequate PVR on ventilator settings.

\section{Conclusion:-}

- We concluded that, patient with severe uncorrected TOF, with O2 saturation of 40\% @ 5lit O2 via venti mask was induced \& conducted uneventfully with digilent pre-operative preparations and well planned anaesthetic technique.

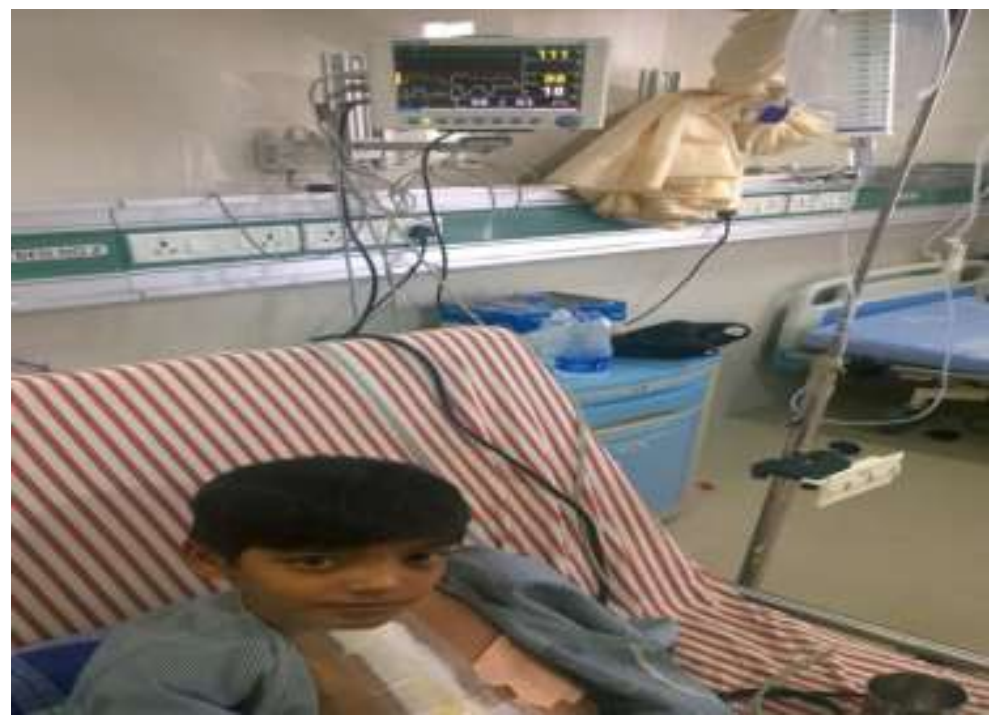




\section{References:-}

1. Rauch $\mathrm{r}$, hofbeck $\mathrm{m}$, zweier c, koch a, zink s, trautmann u, et al. comprehensive genotype-phenotype analysis in 230 patients with tetralogy of fallot. $j$ med genet. 2010 may. 47(5):321-31.

2. Saxena , a. congenital heart disease in india: a status report. indian journal of pediatrics, 2005, 72: 595-598.

3. Spektor, m, donson, da, pflieger, k. tetralogy of fallot. 2009.

4. Tetralogy of fallot anaesthesia tutorial of the week 21918 th april $2011 \mathrm{dr}$ lucy hepburn great ormond street hospital nhs trust correspondence to: hepbul@gosh.nhs.uk

5. Aptiz c, webb g, redington a. tetralogy of fallot. lancet 2009 374: 1462-71

6. Singh v. tetralogy of fallot: surgical perspective, treatment and management. e-medicine http://emedicine.medscape.com/article/904652 (accessed 8th april 2011)

7. Woodward L. J, Kam P. C. A. Ankylosing spondylitis: recent developments and anaesthetic implications. Anaesthesia 2009; 64: 540-548

8. Saringcarinkul A. Anesthetic considerations in severe ankylosing spondylitis. Chiang Mai Med J 2009; 48(2): 57-63. 